\title{
Oficina de mobilização social em Hanseníase: relato de experiência
}

\author{
Leprosy social mobilization workshop: an experience report
}

Taller de movilización social con la Lepra: un relato de experiencia

\section{Daisy de Rezende Figueiredo Fernandes', Paulo Celso Prado Telles Filho' \\ 'Universidade Federal dos Vales do Jequetinhonha e Mucuri. Curso de Enfermagem. Diamantina, MG}

Submissão: 29/08/2008

Aprovação: $21 / 10 / 2008$

\section{RESUMO}

O objetivo do presente estudo foi descrever o relato de experiência de uma Oficina de Mobilização Social e Abordagem Teórica em Hanseníase, entre acadêmicos de enfermagem. Como metodologia utilizou-se o relato de experiência da referida oficina. Entre as três etapas da sua realização, destacaram-se consecutivamente como principais itens os discursos sobre o tema, o registro de dúvidas e Questionamentos em fichas, as discussões, os debates, a exibição de informações técnicas e depoimentos, as dramatizações, a elaboração de materiais educativos para futuras práticas acadêmicas e finalmente, o estudo teórico. Na avaliação feita pelos participantes, percebeu-se um aprimoramento na abordagem da hanseníase.

Descritores: Hanseníase; Enfermagem; Saúde.

\section{ABSTRACT}

The aim if the present study was to describe the report of the experience of a Social Mobilization and Theoretical Approach to Leprosy workshop among nursing academics. As methodology it was used the experience of the referred workshop amongst the three stages of its accomplishment, the main topics which stood out were, consecutively: speeches on the theme, record of doubts, Questionnaires which provide feedback on the matter, discussions, debates, exhibition of technical information and accounts, role plays, elaboration of educational materials for future academic practices and finally, the theoretical study. In the evaluation done by the participants an advance could noticed in the approach to leprosy.

Descriptors: Leprosy; Nursing; Health.

\section{RESUMEN}

El objetivo del presente estudio es describir el relato de la experiencia de la Taller de Movilización Social y del Abordaje Teórico relacionado con la lepra en los estudiantes del curso de Enfermería. La metodología utilizada fue el relato de experiencia del referido taller. Entre las tres etapas de su realización se destacan como puntos principales: los discursos sobre el tema, el registro de las dudas y reflecciones en fichas, el registro de los debates, la exposición de las informaciones técnicas, las dramatizaciones, la elaboración de materiales educativos para prácticas futuras con alumnos y por último, estudio teórico. En la evaluación realizada por los participantes, se notó Que existe un abordaje aprimorado de la lepra.

Descriptores: Lepra; Enfermería; La salud. 


\section{INTRODUÇÃO}

Questões relacionadas à saúde permeiam debates políticos em diversos países, buscando soluções e modelos de políticas, Que possam responder às suas indagações. No final do século XIX, observamos a conformação de modelos de proteção social de menor ou maior abrangência sendo o Brasil, um possível exemplo deste último. A garantia do direito à saúde para todos e de forma igualitária entre os brasileiros se configurou em 1988, com a promulgação da Constituição Federal e a idealização e consolidação do Sistema Único de Saúde-SUS, no mesmo ano ${ }^{(1,2)}$.

Daquele período até os dias atuais, houve avanços e retrocessos mas o sistema se fortaleceu pela construção permanente. Esse se mostrou como um modelo de atenção à saúde com princípios balizadores centrados na integralidade, na universalidade e na equidade da atenção bem como, na participação da comunidade e na descentralização da gestão ${ }^{(3,4)}$.

Paradoxalmente, os grandes avanços percebidos entre duas décadas na área da saúde, não puderam ser também percebidos na área da educação. As políticas de educação profissional sempre foram alvo de crítica e assunto polêmico em nosso país, sendo esta tratada com grande desprestígio e aQuém de propiciar uma real articulação entre educação e trabalho ${ }^{(5)}$.

Há consenso entre os observadores da reforma sanitária brasileira, Que um dos mais graves problemas do SUS refere-se à formação dos recursos humanos para o setor. Acrescentam que é freqüente a constatação do despreparo dos profissionais recém-formados, para atuarem na complexidade inerente ao sistema de saúde, compreender a sua gestão e a ação de controle social da sociedade. Na tentativa de minimizar tal situação, foram criadas parcerias e estratégias governamentais e não governamentais, em busca de práticas inovadoras de educação em saúde. Projetos foram estruturados objetivando contribuir para a formação de profissionais críticos e sensíveis às necessidades da população brasileira. Uma dessas necessidades pertence ao Quadro de doenças negligenciadas, destacando neste artigo a hanseníase ${ }^{(6)}$.

Tem-se que apesar da morbidade mundial estar se estabilizando e com tendência de declínio, a doença permanece endêmica entre as diversas regiões do Brasil, aparecendo em segundo lugar no panorama mundial e perdendo somente para a Índia. Outro agravante é Que apesar da descoberta de seu agente etiológico e da cura, a hanseníase ainda carrega consigo uma história de medo, de preconceitos e de segregação Que marca suas vítimas e, por vezes, seus familiares, por toda uma existência ${ }^{(7-9)}$.

Em presença deste cenário, vale destacar Que em uma Universidade Federal localizada no Vale do Jequitinhonha -MG, foi observado no Curso de Graduação em Enfermagem a fragilidade com Que o tema hanseníase era abordado na instituição, apesar de sua localização em área endêmica. Após esta constatação, optou-se pelo desenvolvimento de uma Oficina de Mobilização social e abordagem teórica em hanseníase, cujo propósito foi identificar os conhecimentos adQuiridos pelos alunos, visando proporcionar ao grupo novos valores e conhecimentos em saúde coletiva e, especificamente, relacionado à hanseníase.

O objetivo do presente estudo foi descrever a experiência de uma Oficina de Mobilização Social e Abordagem Teórica em Hanseníase.

\section{METODOLOGIA}

Trata-se de um relato de experiência, a Qual se realizou através de uma oficina, buscando propiciar aos participantes um ambiente acolhedor, com estratégia de aprendizagem estimulante, visando a criatividade na busca de soluções ${ }^{(10)}$.

É conveniente citar ainda, a definição de oficina como modalidade de um processo educativo Que segue a adequação e a seQüência de passos a serem dados, para Que se chegue a um objetivo, constituindose como um espaço privilegiado de criação e descobertas e onde os produtos construídos, apresentam aspectos da contribuição de cada $u^{(11)}$.

\section{RELATO DE EXPERIÊNCIA}

No período de $8: 00$ h̀̀ $12: 00$ h e das $14: 00$ h̀̀ $18: 00$ do dia 29 de abril de 2008 e de 8:00h às 12:00h do dia 05 de maio de 2008, deu-se a realização da Oficina de Mobilização Social e Abordagem Teórica em Hanseníase, com a participação de 33 acadêmicos do Curso de Graduação em Enfermagem da Universidade Federal dos Vales do Jequitinhonha e Mucuri - UFVIM tendo como moderadores, uma docente universitária e uma fisioterapeuta da Gerência Regional de Saúde do Estado de Minas Gerais, considerada referência técnica na área de hanseníase.

Vale ressaltar Que cada fase da referida oficina teve a duração de Quatro horas e Que o relato será dividido em três etapas tal como foi realizado, buscando facilitar o entendimento.

$\mathrm{Na}$ primeira fase, deu-se o discurso dos participantes entre o grupo em relação aos conhecimentos adQuiridos sobre a hanseníase tanto na vida pessoal Quanto acadêmica; o registro de dúvidas e Questionamentos em fichas de cartolina Que foram afixadas em um painel denominado painel de dúvidas; discussões e debates sobre conceitos trazidos, situações conhecidas envolvendo portadores e ex-portadores sempre enfatizando as Questões do estigma e dos preconceitos e a relação destes, com o diagnóstico tardio e as seqüelas. Desfez-se o grupo e houve a exibição de vídeo fornecido pelo Ministério da Saúde sobre informações técnicas e depoimentos de pacientes, familiares e profissionais de saúde dentre outros, como material de apoio e de divulgação. Houve nova formação do grupo e nessa fase, buscou-se estimular o discurso no que concerne ao mecanismo de transmissão, ao tratamento medicamentoso, às incapacidades físicas e suas prevenções e outros temas e dúvidas, Que de maneira aleatória surgiram. Vale ressaltar a presença dos moderadores, Que estimulavam os debates e propiciavam consistência teórica às discussões. Para o enceramento desta fase, os participantes foram reconduzidos até o painel de dúvidas, no Qual retiraram uma ou mais fichas de cartolina independentemente de terem sido preenchidas por eles ou por outro participante e novamente, houve a formação do grupo. Incentivados pela condução dos moderadores, responderam à maioria das antigas dúvidas e Questionamentos contidos nas fichas.

Na segunda fase houve a realização de dramatizações, nas Quais os participantes se colocaram em situações do cotidiano dos doentes ou de casos suspeitos, com o objetivo de discutir as dificuldades enfrentadas, as situações de discriminação e estigma experimentadas pelos mesmos.

Seguiu-se à elaboração de materiais educativos a serem utilizados 
nas futuras práticas acadêmicas, Que foram a criação e a encenação de peça teatral, a elaboração de mensagem a ser veiculada nas estações de rádio municipal e a produção de um texto, para ser editado em jornal de grande circulação no município em Questão, bem como o planejamento e execução de faixas de tecido, para serem afixadas em lugares públicos.

$\mathrm{Na}$ terceira e última fase, realizou-se a abordagem teórica sistematizada sobre a hanseníase, resgatando os conceitos elaborados no dia anterior e exibindo as propostas do Plano Nacional de Eliminação da Hanseníase (PNEH), do Ministério da Saúde.

É importante destacar Que ao final da oficina foi distribuído um impresso, solicitando Que os acadêmicos apontassem aspectos positivos e negativos bem como sugestões, para uma próxima oficina. A análise destas fichas permitiu-nos destacar enQuanto aspectos positivos Que o assunto foi abordado de maneira simples, dinâmica e interativa, tendo facilitado a compreensão e o acesso às informações assim como, o rompimento com antigos tabus e mitos e a apreciação dos participantes, em trabalhar como um grupo. Como aspecto negativo e sugestão foi apontada apenas a necessidade de mais tempo para a realização das atividades da segunda fase, a Qual merecerá atenção especial nas próximas edições da oficina em foco.
Finalizou-se esse relato de experiência destacando-se a excelência do modelo pedagógico adotado, bem como a superação dos desafios propostos aos acadêmicos nesta oficina.

\section{CONSIDERAÇÕES FINAIS}

A descrição deste relato de experiência acerca da Oficina de Mobilização Social e Abordagem Teórica em Hanseníase permitiu a ampliação do conhecimento científico em relação à mesma, entre os participantes.

Vale ressaltar, Que a utilização de oficinas na educação de adultos possibilita a estes ocupar o lugar de sujeitos na construção do conhecimento e ao educador, o de facilitador deste processo sendo considerado na atualidade, de grande utilidade.

Tais oficinas facilitam a formação de profissionais criativos, críticos, reflexivos e com compromisso político sendo inclusive capazes de enfrentar situações de maior complexidade Que se apresentam no cotidiano profissional, uma vez Que estas incitam discussões entre os participantes do grupo, Que certamente irão proporcionar excelente repercussão na comunidade bem como maximizar, as possibilidades de intervenções futuras.

\section{REFERÊNCIAS}

I. Ministério da Saúde (BR). Conselho Nacional de Secretários Municipais de Saúde. O SUS de A a Z: garantindo saúde nos municípios. Brasília: Ministério da Saúde; 2005.

2. Cunha JPP, Cunha RE. Sistema Único de Saúde: princípios. In: Ministério da Saúde (BR). Gestão Municipal de Saúde: textos básicos: Rio de Janeiro: Ministério da Saúde; 200I .

3. Baptista TWF. História das políticas de saúde no Brasil: a trajetória do direito à saúde. In: Matta GC, Pontes, ALM. Políticas de Saúde: organização e operacionalização do sistema único de saúde. Rio de Janeiro: EPSJV/Fiocruz; 2007.

4. Ministério da Saúde (BR). Secretaria de Atenção à Saúde. Política Nacional de Atenção Básica. Brasília: Ministério da Saúde; 2007.

5. Sório RER. Educação e trabalho em saúde: perspectivas de debate sob os marcos legais da educação profissional. In: Ministério da Saúde (BR). Gestão Municipal de Saúde: textos básicos: Rio de Janeiro: Ministério da Saúde; 200I .

6. Ceccim RB, Bilibio LFS. Articulação com o segmento estudantil da área da saúde: uma estratégia de inovação na formação de recursos humanos para o SUS. In: Ministério da Saúde (BR). Secretaria de Gestão do Trabalho e da Educação na Saúde. VER - SUS Brasil: cadernos de textos. Brasília (DF): Ministério da Saúde; 2004.

7. Ministério da Saúde (BR). Departamento de Ciências e Tecnologia. Oficina de prioridades na pesQuisa em saúde. Informativo DECIT 2008.

8. World Health Organization (WHO). Global leprosy situation, 2007. Weekly Epidemiol Record 2007; 25(82): 225-32.

9. Mattos DM, Fornazari SK. A lepra no Brasil: representação e práticas de poder. Cad Ética Filosofia Política 2005;6(I) :45-57.

10. Bastiani JAN, Padilha MICS. Experiência dos Agentes Comunitários de Saúde em Doenças Sexualmente Transmissíveis. Rev Bras Enferm 2007; 60(2): 233-6.

11. Corcione D. Fazendo oficina. In: Brasil. Ministério da Saúde. Secretaria de Gestão do Trabalho e da Educação na Saúde. VER - SUS Brasil: cadernos de textos. Brasília: Ministério da Saúde, 2004. 